\title{
EFEITO DO TRATAMENTO TÉRMICO SOBRE FÓRMULAS INFANTIS: UMA REVISÃO
}

\section{Effect of heat treatment on infant formulas: a review}

\author{
Júlia d'Almeida Fracisquini', Lauane Nunes ${ }^{1}$, Evandro Martins ${ }^{l}$, Rodrigo Stephani', \\ Italo Tuler Perrone ${ }^{3 *}$, Antônio Fernandes de Carvalho ${ }^{l}$
}

\begin{abstract}
RESUMO
O primeiro alimento do lactente corresponde ao leite materno o qual deve, dentre outras funções, suprir as necessidades nutricionais da criança e gerar proteção imunológica. Em certos casos, mães podem ser ver impossibilitadas de realizar o aleitamento materno, necessitando de substitutos. Hoje o substituto que melhor mimetiza o leite humano corresponde às formulas infantis. Para elaboração deste alimento são necessários sucessivos tratamentos térmicos os quais podem ocasionar para o produto problemas tanto do ponto de vista tecnológico e sensorial quanto do plano nutricional o que pode acarretar em prejuízos para a saúde da criança. Portanto, as indústrias alimentícias precisam gradativamente aprimorar as técnicas de elaboração das fórmulas infantis com a finalidade de se igualar cada dia mais ao leite materno diminuindo assim as suas consequências negativas para a saúde da criança.
\end{abstract}

Palavras-chave: amamentação; lactente; leite materno.

\begin{abstract}
The first food of the infant corresponds to the mother's milk which must, among other functions, supply the nutritional needs of the child and generate immunological protection. In some cases, mothers may be unable to breastfeed, requiring substitutes. Nowadays the substitute that best mimics human milk corresponds to the infant formulas. The preparation of this food requires successive heat treatments which

1 Universidade Federal de Viçosa, Departamento de Tecnologia de Alimentos, Viçosa, MG, Brasil

2 Universidade Federal de Juiz de Fora, Departamento de Química, Juiz de Fora, MG, Brasil.

3 Universidade Federal de Juiz de Fora (UFJF), Departamento de Ciências Farmacêuticas, Juiz de Fora, MG, Brasil. E-mail: italotulerperrone@gmail.com

* Autor para correspondência.
\end{abstract}

Recebido / Received: 13/03/2018

Aprovado / Approved: 13/04/2018 
can cause to the product problems both from the technological and sensorial point of view as well as from the nutritional aspect, which can lead to damages to the child's health. Therefore, the food industry needs to gradually improve the elaboration techniques of infant formulas in order to be more similar to breast milk, thus reducing its negative consequences for the health of the child.

Keywords: breast-feeding; infant; breast milk.

\section{INTRODUÇÃO}

A primeira alimentação da criança corresponde ao aleitamento materno sendo este indispensável para o seu crescimento e desenvolvimento. Sabe-se que a alimentação no decorrer dos primeiros anos de vida é de extrema importância para a formação dos hábitos alimentares na fase adulta. O leite humano é um fluido complexo com variações composicionais ao longo do dia, entre uma mamada e outra, e durante os distintos períodos dalactação. Sua composição pode ser afetada pela idade da mãe, dieta, fatores étnicos, peso adquirido durante a gestação, e individualidade genética. A recomendação da Organização Mundial da Saúde (OMS) é de que o aleitamento materno seja exclusivo ao longo dos seis primeiros meses de vida da criança (ANDREAS, 2015; ZOU et al., 2016).

O leite materno compensa as deficiências do neonato gerando proteção imunológica, evitando o surgimento de patologias e suprindo as necessidades nutricionais da criança. Desta forma, o aleitamento materno é indicado tanto do ponto de vista nutricional e imunológico, quanto no plano psicológico uma vez que favorece o vínculo mãe-filho (BLANCHARD et al., 2013; ANDREAS, 2015). Porém, em alguns casos, mães impossibilitadas de amamentar necessitam de uma alternativa para substituir o leite materno (EUCLYDES, 2014).

\section{REFERENCIAL TEÓRICO}

\section{Diferença composicional entre o leite materno e bovino}

O leite de vaca ainda é a principal alternativa para alimentação de crianças não amamentadas por leite materno, apesar de ser contraindicado por evidências científicas da inadequação de sua composição em relação às necessidades nutricionais da criança e à sua capacidade funcional e renal (EUCLYDES, 2014). Sabe-se que o leite materno contém três a quatro vezes menos proteína do que o leite de vaca, não apresentando $\beta$-lactoglobulina e possuindo uma maior quantidade de proteína do soro (THOMPKINSON; KHARB, 2007). O mesmo possui quase o dobro de carboidratos, vestígios de oligossacarídeos e três vezes mais ácidos graxos poliinsaturados de cadeia longa. Além de maior teor de cisteína e imunoglobulina e menores níveis de tirosina e triptofano (BALLARD; MORROW, 2013).

Também, em comparação com o leite de vaca, o leite materno contém quase três vezes mais ácido linoleico. O conteúdo mineral do leite materno, principalmente cálcio e fósforo, éinferior ao bovino. Em termos de vitaminas, o leite materno contém mais vitaminas $\mathrm{E}$ e $\mathrm{C}$, e menos vitaminas B1, B2 e B6 em comparação com o leite bovino (JIANG; GUO, 2014).

As imunoglobulinas do início da lactação e os numerosos anticorpos contra patógenos bacterianos, vírus e leveduras são encontrados somente no leite humano (ANDREAS et al., 2015). Aliadas a tais diferenças compo- 
sicionais, deve-se ainda considerar a menor biodisponibilidade de nutrientes do leite de vaca e as perdas adicionais dos nutrientes pelo tratamento térmico indispensável.

Possíveis intolerâncias ao leite de vaca ou de outras espécies pelos lactentes podem acontecer com possibilidade de deficiências de ferro e de ácidos graxos poli-insaturados de cadeia longa, anemia, alergias, sobrecarga renal, deficiencias neurológias, desnutrição, hipocalcemia neonatal, aminoacidemia e refluxo em decorrência da limitada capacidade gástrica e imaturidade digestiva e renal (BLANCHARD et al., 2013; ZOU et al., 2016).

\section{Mercado, definição e composição das fórmulas infantis}

A fórmula infantil representa cerca de $70 \%$ do mercado mundial de alimentos infantis e, em 2010, essa porcentagem foi de cerca de 40\% (HAPPE; GAMBELLI, 2015). O mercado global de alimentos para bebês e fórmulas infantis atingiu cerca de US\$ 48 bilhões até 2016. Em 2015, de longe, a região asiática dominou cerca de $65 \%$ do mercado global de fórmulas, apenas a China representa mais de $40 \%$ do mercado global (EUROMONITOR INTERNATIONAL, 2016). Quatro empresas multinacionais consolidaram seu domínio no mercado de fórmulas infantis, incluindo Nestlé, Danone, Abbott e Mead Johnson (AFFERTSHOLT; PEDERSEN, 2017).

A principal agência regulamentadora para fórmulas infantis em nível internacional é o Codex Alimentarius Committee (Codex) estabelecido pela Organização das Nações Unidas (ONU). Segundo o Codex, fórmula infantil corresponde ao "substituto do leite materno especialmente fabricado para satisfazer, por si só, os requisitos nutricionais dos lactentes durante os primeiros meses de vida atéa introdução de alimentação complementar adequada".
As fórmulas infantis podem ser classificadas em diferentes categorias: para prematuros, lactentes (primeiros seis meses de vida); de seguimento para lactentes (a partir dos 6 meses de idade); de seguimento para crianças de primeira infância (12 meses a 3 anos de idade) e especiais (CAC/STAN 72-1981; BLANCHARD et al., 2013).

A categoria das fórmulas infantis para prematuros relaciona-se com a necessidade de cuidados especiais em virtude da imaturidade dos sistemas imunológico e digestivo ainda em formação. Tais alimentos devem apresentar teor energético e proteico e de ácidos graxos essenciais elevado (BLANCHARD et al., 2013; EUCLYDES, 2014).

As fórmulas destinadas aos lactentes usam como matéria prima o leite de vaca, concentrado proteico de soro, soro de leite desmineralizado, carboidratos e óleos vegetais podendo ou não ser acrescido de minerais como o ferro. Para os lactentes de segmento, recomenda-se a utilização de fórmulas infantis que apresentam uma maior variedade composicional, devido àampla faixa etária abrangida (CAC/STAN 72-1981).

Já as fórmulas especiais, apresentam composição de acordo com as necessidades nutricionais específicas de cada caso. Existem, por exemplo, as fórmulas com proteína hidrolisada, à base de soja, anti-refluxo, isentas de lactose, para erros inatos de metabolismo e extensamente hidrolisadas ou elementares (CAC/STAN 72-1981).

As fórmulas para lactentes (de partida e de seguimento) são as mais usadas. Basicamente tais fórmulas devem, após reconstituição, conter no mínimo $60 \mathrm{kcal} / 100 \mathrm{~mL}$ e no máximo $70 \mathrm{kcal} / \mathrm{mL}$. Com relação às proteínas grande parte é proveniente do leite de vaca integral e soro de leite sendo que a quantidade de aminoácidos essenciais e semiessenciais devem estar no mínimo igual ao contido na proteína de referência (leite humano) (BLANCHARD et al., 2013; EUCLYDES, 2014). 
Há uma redução na quantidade de gordura saturada, sendo que o lipídeo nesta fórmula vai ser parte proveniente da gordura láctea e parte proveniente de distintas fontes vegetais (EUCLYDES, 2014; JIANG; GUO, 2014). O conteúdo dos ácidos graxos trans das fórmulas deve ser o mais baixo possível, aproximadamente $3 \%$ dos ácidos graxos totais (THOMPKINSON; KHARB, 2007).

Grande parte das fórmulas apresenta acréscimo apenas de lactose para atingir a quantidade existente no leite humano, mas em outras existe também a adição de misturas de outros carboidratos como sacarose, maltose-dextrina, polímeros de glicose e amido (EUCLYDES, 2014; ANDREAS, 2015). Por fim, para aproximar ainda mais do leite materno, podem ser adicionados alguns ingredientes como nucleotídeos, ácidos graxos de cadeia longa, probióticos/prebióticos e amilopectina (EUCLYDES, 2014).

\section{Métodos industriais de produção de fórmulas infantis}

As fórmulas infantis podem ser encontradas em três formas: pronta para o consumo, líquida concentrada e em pó. A fórmula líquida pronta para consumo não tem a necessidade de ser misturada com água, apresentando já a quantidade adequada dos nutrientes para atingir a necessidade nutricional do lactente e evitando erros de diluição. No entanto, esta versão tem um preço relativamente elevado, sendo maiores os gastos com sua produção, transporte e distribuição o que limita sua comercialização (SMITH et al., 2011; KLIEGMAN et al., 2014).

As fórmulas líquidas concentradas e as fórmulas em póprecisam de uma diluição/ reconstituição, respectivamente, em água, a qual pode ser excessiva ou insuficiente para atingir as necessidades nutricionais da criança. Estes tipos de fórmulas também têm o problema de contaminação após o processo de diluição ou reconstituição. As fórmulas líquidas concentradas são mais onerosas em relação à sua produção, transporte, distribuição e armazenamento e possuem um menor prazo de validade quando comparadas com as em pó. A extensão do prazo de validade, menos problemas com armazenamento e perda do produto e os menores custos das fórmulas em pófazem com que as mesmas sejam as mais difundidas e procuradas pelo mercado consumidor (SMITH et al., 2011; KLIEGMAN et al., 2014).

As fórmulas preparadas na forma em pópodem ser fabricadas usando o processo de "mistura seca" ou o processo "úmido/ pulverização" ou ainda em alguns casos, podem-se combinar os processos. No caso da fabricação de fórmulas via mistura a seco, os ingredientes são recebidos dos fornecedores em forma de pó e são misturados em conjunto para se obter a mistura uniforme de macro e micronutrientes. As vantagens de usar o processo de mistura seca incluem menor gasto energético durante a produção e menor investimento em equipamentos, construção e manutenção. A principal desvantagem reside no fato de que a qualidade microbiológica deste processo é dependente da qualidade da matéria prima usada para formar a mistura uma que vez que não há tratamento térmico para destruir as bactérias no produto final (BLANCHARD et al., 2013; MEHTA; DEETH, 2016).

\section{Tratamento térmico ao longo da produção de fórmulas infantis por via úmida}

Com a finalidade de reduzir os riscos microbiológicos associados ao processo de mistura a seco, a via úmida é o método mais usado na produção de fórmulas infantis em pó, com a principal vantagem o fato de que ferramentas de qualidade podem ser aplicadas para monitorar e controlar as etapas do processo. $\mathrm{Na}$ fabricação por via 
úmida, a matéria prima inicial é obtida na forma de pó, sendo assim esta já sofreu um prévio tratamento térmico, específico para cada ingrediente, o que pode trazer interferência do ponto de vista tecnológico, sensorial e nutricional. Tais matérias primas serão misturadas com água e óleo $\left(72^{\circ} \mathrm{C}\right.$ por 15 segundos). Esses ingredientes homogeneizados serão, em seguida, tratados termicamente, com diferentes binômios tempo/ temperatura como $95^{\circ} \mathrm{C}$ por 2 minutos ou $140{ }^{\circ} \mathrm{C}$ por 5 segundos. Este binômio muitas das vezes apresentará temperaturas próximas/ acima de $100^{\circ} \mathrm{C}$ e é particular de cada empresa de acordo com seu processamento. Por fim, ocorre a concentração a vácuo desta mistura, sendo aqui a temperatura próxima de $60{ }^{\circ} \mathrm{C}$, com evaporação da água até concentração de sólidos entre $40 \%$ e $50 \%$ (BLANCHARD et al., 2013; SCHU et al., 2016).

\section{Efeito do tratamento sobre as fórmulas infantis}

O tratamento térmico que as fórmulas infantis sofrem é necessário para que as mesmas tenham qualidade microbiológica não sendo um veículo transmissor de doenças para a criança. Portanto, tal tratamento térmico afeta positivamente a conservação das fórmulas infantis por ser o principal agente responsável pela mortalidade de microrganismos deterioradores e patogênicos do produto (EUCLYDES, 2014).

Porém, infere-se que durante o processo de fabricação deste alimento, principalmente para garantir a inocuidade do produto, são realizados sucessivos aquecimentos o que pode resultar em significativas alterações nutricionais e reológicas dos componentes (BLANCHARD et al., 2013; JIANG; GUO, 2014).

$\mathrm{O}$ aquecimento e armazenamento a temperaturas mais altas pode proporcionar reações de escurecimento não enzimáticas tais como a oxidação do ácido ascórbico ao ácido desidroascórbico ou ainda a caramelização a qual ocorre na presença de açúcares (MOLTÓPUIGMARTÍ et al., 2011). Também, pode acontecer a reação de Maillard a qual causa a redução da qualidade dos produtos lácteos quando aquecidos resultando na formação de determinados produtos como os furfurais e carboximetilisina frequentemente associados com a destruição ou redução do valor nutricional de aminoácidos essenciais para o lactente como arginina, lisina, metionina e triptofano, além de reduzir a digestibilidade do alimento (MEHTA; DEETH, 2016).

Quanto mais cedo a exposição da criança a tais produtos, maior será a interferência sobre a sua saúde. Assim, um pool endógeno excessivo na infância pode resultar em um papel patogênico no desenvolvimento e progressão de diferentes doenças oxidativas na fase adulta (diabetes, resistência à insulina, falência renal crônica, doenças cardiovasculares, desordens neurológicas, envelhecimento, estresse oxidativo, danos proteicos, hipertensão, disfunção endetolial, patologia na retina, osteoposose, artrite). Em contrapartida, trabalhos avaliaram a possível atividade antioxidante, anti-hipertensiva, prebiótica e antimicrobiana dos produtos de reação de Maillard, principalmente como melanoidinas quando ingeridos em quantidades adequadas (PATRIGNANI et al., 2016).

\section{Efeito do tratamento térmico sobre os macronutrientes e os micronutrientes das fórmulas infantis}

$\mathrm{O}$ efeito do tratamento térmico sobre os aspectos nutricionais pode ocorrer à nível de macro e micronutrientes, o que afetará positivamente ou negativamente a característica nutricional do produto (TERAMOTO et al., 2010). Dentre as proteínas deste alimento, as caseínas são pouco afetadas pelo aquecimento, mas outras funções atribuídas 
à elas podem sofrer modificações devido ao aquecimento. Com o tratamento térmico a kapa-caseína pode perder sua função assim como a $\beta$-caseína (redução da biodisponibilidade de cálcio e zinco no leite humano) (LÖNNERDAL, 2014).

As soro proteínas são mais susceptíveis a ação dos tratamentos térmicos, podendo ter suas características funcionais e nutricionais alteradas. A $\alpha$-lactoalbumina pode perder sua capacidade de se ligar a cálcio e ao zinco diminuindo também a biodisponibilidade desses nutrientes. Já a lactoferrina pode perder o seu papel de ação microbiana na presença de calor (GOLINELLI et al, 2014). As $\beta$-lactoglobulinas apesar de serem inexistentes no leite humano podem estar presentes nas fórmulas infantis. As mesmas são amplamente afetadas pelo calor tornando-se até mesmo, em alguns casos, insolúveis. Por fim, em produtos com sucessivos tratamentos térmicos é possível que haja a agregação proteica resultante da interação entre $\beta$-lactoglobulinas e $\kappa$-caseínas por meio de ligações dissulfídicas. Tais interações aumentam o grau de hidrofobicidade do produto podendo interferir em suas propriedades (NEVES, 2015).

Em relação aos lipídeos, o calor favorece a hidrólise e interesterificação de glicerídeos. Durante a fabricação de fórmulas infantis existem mudanças, na qualidade e quantidade, dos ácidos graxos de cadeia curta os quais podem ser sensivelmente alterados (PESTANA et. al. 2015). Há também, indução da cristalização da lactose e aumento da atividade de água com o aquecimento e armazenamento prolongado, o que acelerará a oxidação lipídica (CHENG et al., 2017). Sendo assim quando alterados pela oxidação e pelo aquecimento os lipídeos podem perder suas funções que são fundamentais para a criança (ZOU et al., 2016).

O calor também pode afetar os carboidratos, sendo que a isomerização da lactose em lactulose e ácidos orgânicos uma das consequências do aquecimento (ZHANG et al., 2010).

Em relação aos micronutrientes, percebe-se que as vitaminas lipossolúveis $\mathrm{A}$, $\mathrm{D}, \mathrm{E}, \mathrm{K}$ e algumas do complexo $\mathrm{B}$ (biotina e riboflavina) são relativamente estáveis ao aquecimento aplicado às fórmulas infantis. Já as vitaminas hidrossolúveis são as mais afetadas pelo tratamento térmico, sendo a vitamina $\mathrm{C}$ e a tiamina aquelas que sofrem maior interferência. Dentre as vitaminas hidrossolúveis, a biotina e riboflavina são as menos afetadas (CORREIA et al., 2008). A perda de vitamina évariável e dependente do binômio tempo/temperatura que o produto será submetido (LESKOVA, et. al. 2006).

Dentre os minerais, o cálcio é um dos mais afetados pela ação do calor podendo ser internalizado nas micelas de caseína e se tornar indisponível para absorção da criança. Além disso, o cálcio pode ser perdido durante o aquecimento por meio das incrustações nos equipamentos juntamente com outros minerais e proteínas. O teor de fosfato inorgânico é elevado por favorecer a hidrólise dos ésteres de fosfato da caseína e fosfolipídios, diminuindo a disponibilidade de fósforo (WALSTRA et. al., 1999).

\section{Consequência do uso de fórmulas infantis para a saúde do lactente}

A hidrólise da lactose é relativamente lenta no corpo, por isso algumas moléculas podem permanecer intactas no trato digestivo e estimular o desenvolvimento da microbiota intestinal, como bifidobactérias e lactobacilos (THOMPKINSON; KHARB, 2007). Nas fórmulas infantis, são adicionados galacto-oligossacarídeos (GOS), fructo oligosacarídeos (FOS) e inulina, com a finalidade de imitar os beneficios biológicos dos oligossacarídeos presentes no leite materno (BLANCHARD et al., 2013). Em alguns casos, a sacarose pode ser útil para mascarar 
o sabor amargo, como por exemplo, nas fórmulas à base de proteínas hidrolisadas. Portanto, os problemas associados ao excesso da sacarose podem aparecer como maior propensão àdiabetes e obesidade assim como desenvolvimento de cáries dentárias (NGUYEN et al., 2015).

Em resumo, estudos demonstram que crianças não amamentadas com leite materno podem estar predispostas à menor absorção de cálcio, crescimento e integridade do trato gastrointestinal afetados e microbiota intestinal com presença de bactérias maléficas (LIU et al., 2015). Além disso, os lactantes não amamentados com leite materno tornam-se expostos a uma maior incidência de infecções, otite média, gastroenterite, pneumonia, rinite, asma e com maiores chances de obesidade infantil, riscos metabólicos, diabetes tipo 1 e 2, dermatite atópica, doenças cardiovasculares, enterocolite necrotizante, doença celíaca, doença inflamatória intestinal, doenças bucais, leucemia e síndrome de morte súbita infantil. Há também impactos do ponto de vista neurológico afetando o índice de desenvolvimento (QI) podendo resultar em maior pré-disposição a transtornos, déficit de atenção e distúrbios comportamentais (BRAHMA; VALDÉS, 2017).

\section{CONSIDERAÇÕES FINAIS}

As fórmulas infantis são muitas vezes a única fonte de nutrientes durante um período significativo de rápido crescimento e desenvolvimento dos lactentes. Assim, é muito importante que estes produtos proporcionem quantidade e qualidade suficiente dos nutrientes. Com isto, as indústrias alimentícias devem buscar novas formulações e estratégias produtivas que melhor mimetizem as fórmulas infantis ao leite materno, implicando em menor incidência de patologias e permitindo o ideal desenvolvimento e crescimento da criança.

\section{AGRADECIMENTOS}

Ao CNPq, a FAPEMIG e a CAPES pelo apoio financeiro aos projetos e as bolsas de produtividade da equipe do projeto.

\section{REFERÊNCIAS}

AFFERTSHOLT, T.; PEDERSEN, D. Infant Formula: A Young \& Dynamic Market. The World of Food Ingredients, 2017.

ANDREAS, N. J. et al. Human breast milk: A review on its composition and bioactivity. Early Human Development, v. 91, p. 629$635,2015$.

BALLARD, O.; MORROW, A. L. Human Milk Composition Nutrients and Bioactive Factors. Pediatric Clinics of North America, v. 60 , n. 1, p. 49-74, 2013.

BLANCHARD, E. et al. Infant formula food powders. In: BHANDARI B.; BANSAL N.; ZHANG M.; SCHUCK, P, editors. Handbook of food powders. Oxford: Woodhead Publishing Limited, 2013. p. 465-483.

BRAHMA, P.; VALDÉS, V. Benefits of breastfeeding and risks associated with not breastfeeding. Revista Chilena de Pediatria, v. 88, n. 1, p. 15-21, 2017.

CAC (Codex Alimentarius Commission). Joint FAO/WHO Food Standards Programme.

Standard for infant formula and formulas for special medical purposes intended for infants. Adopted as a worldwide Standard in 1981. Amendment: 1983, 1985, 1987, 2011 and 2015. Revision: 2007. CAC/STAN 72-1981.

CHENG, H. et al. High temperature storage of infant formula milk powder for prediction of storage stability at ambient conditions. 
International Dairy Journal, v. 73, p. 166$174,2017$.

CORREIA, L. F. M.; FARAONI, A. S.; PINHEIRO-SANT'ANA, H. M. Efeitos do processamento industrial de alimentos sobre a estabilidade de vitaminas. Alimentos e Nutrição, v. 19, n. 1, p. 83-95, 2008.

EUCLYDES, M. P. Nutrição do lactente: Base científica para uma alimentação saudável. Viçosa: Editora UFV, 2014. 616p.

EUROMONITOR INTERNATIONAL. Market Overview: Identifying New Trends and Opportunities in the Global Infant. Formula Market, Part I. Disponível em: <http:// www.euromonitor.com/market-overviewidentifying-new-trends-and-opportunitiesin-the-global-infant-formula-market-part-i/ report>. Acesso em: 20 ago. 2017.

GOLINELLI, L. P. et al. Functional Aspect of Colostrum and Whey Proteins in Human Milk. Journal of Human Nutrition \& Food Science, n. 2, v. 3, p. 1035, 2014.

HAPPE, R. P.; GAMBELLI, L. Infant formula.In: TALBOT, G. Specialty Oils and Fats in Food and Nutrition - Properties, Processing and Applications. Amsterdam: Elsevier, 2015. Cap. 12, p. 285-315.

JIANG, Y. J.; GUO, M. Processing technology for infant formula. In: GUO, M. (Ed.). Human Milk Biochemistry and Infant Formula Manufacturing Technology. $1^{\text {a }}$ ed. Cambridge: Woodhead, 2014. p. 211-229.

KLIGMAN, R. M. et al. Tratado de pediatria. Rio de Janeiro: Elsevier, 2014. 4992p.

LESKOVA, E. et al. Vitamin losses: Retention during heat treatment and continual changes expressed by mathematical models. Journal of Food Composition and Analysis, v. 19, n. 4, p. 252-276, 2006.

LIU, Z. et al. Human Breast Milk and Infant Formulas Differentially Modify the Intestinal Microbiota in Human Infants and Host Physiology in Rats. American Society for Nutrition, v. 12, n. 2, p. 191-199, 2015.

LONNERDAL, B. Infant formula and infant nutrition: bioactive proteins of human milk and implications for composition of infant formulas. The American Journal of Clinical Nutrition, v. 99, n. 3, p. 712S-7S, 2014.

MEHTA, B. M.; DEETH, H. C. Blocked Lysine in Dairy Products: Formation, Occurrence, Analysis, and Nutritional Implications. Comprehensive Reviews in Food Science and Food Safety, v. 15, n. 1, p. 206-218, 2016.

MOLTÓ-PUIGMARTÍ, C. et al. Effects of pasteurisation and high-pressure processing on vitamin $\mathrm{C}$, tocopherols and fatty acids in mature human milk. Food Chemistry, v. 124, n. 3, p. 697-702, 2011.

NEVES, L. N. O. Desenvolvimento e aplicação de metodologias analíticas para avaliação de indicadores de tratamento térmico em leite UHT. 2015. 151p. Dissertação (Mestrado Profissional em Ciência e tecnologia do leite e Derivados) - Universidade Federal de Juiz de Fora, Juiz de Fora, 2015.

NGUYEN, T. T. P. et al. A comprehensive review on in vitro digestion of infant formula. Food Research International, v. 76, n. 3, p. 373-386, 2015.

PATRIGNANI, M. et al. E. In vivo effects of Maillard reaction products derived from biscuits. Food Chemistry, v. 196, p. 204$210,2016$. 
PESTANA, M. J. et al. Effects of Pasteurization and Ultra-High Temperature Processes on Proximate Composition and Fatty Acid Profile in Bovine Milk. American Journal of Food Technology, n. 10, n. 6, p. 265-272, 2015.

SCHUG, I. S.; ULRICH, K.; FOERST, U. K. P. Modeling spray drying of dairy products Impact of drying kinetics, reaction kinetics and spray drying conditions on lysine loss. Chemical Engineering Science, v. 141, p. 315-329, 2016.

SMITH, J. D. et al. Pharmacists'guide to infant formulas for term infants. Journal of the American Pharmacists Association, v. 51, n. 3, p. e28-e37, 2011.

TERAMOTO, S. et al. A first fatal neonatal case of Enterobactersakazakii infection in Japan. Pediatrics International, v. 52, n. 2, p. 312-313, 2010.
THOMPKINSON, D. K.; KHARB, S. Aspects of Infant Food Formulation. Comprehensive Reviews in Food Science and Food Safety, v. 6, p. 79-102, 2007.

WALSTRA, P. et al. Dairy Technology: principles of milk properties and processes. Food Science and Technology. New York: CRC Press, 1999. 752 p.

ZHANG, Z. et al. Determination of lactulose in foods: a review of recent research. International Journal of Food Science and Technology, v. 45, n. 6, p. 1081-1087, 2010.

ZOU, L. et al. Infant Formula Fat Analogs and Human Milk Fat: New Focus on Infant Developmental Needs. Annual Review of Food Science and Technology, v. 7, p. 139$165,2016$. 